\title{
Secagem da polpa de jambolão (Syzygium \\ cumini) em secador de leito de jorro: \\ efeito da clara de ovo como agente \\ carreador de secagem na \\ qualidade do produto
}

\author{
Drying of jambolão (Syzygium cumini) pulp in spouted \\ bed dryer: effect of egg white as drying carrier agent on \\ product quality
}

\author{
Andressa Costa Soares ${ }^{1}$ (D), Nádia Rosa Pereira ${ }^{1 *}$ (D) \\ ${ }^{1}$ Universidade Estadual do Norte Fluminense Darcy Ribeiro (UENF), Laboratório de Tecnologia de Alimentos (LTA), \\ Campos dos Goytacazes/RJ - Brasil
}

${ }^{*}$ Corresponding Author: Nádia Rosa Pereira, Universidade Estadual do Norte Fluminense Darcy Ribeiro (UENF), Laboratório de Tecnologia de Alimentos (LTA), Av. Alberto Lamego, 2000, sala 107, CEP: 28013-602, Campos dos

Goytacazes/RJ - Brasil, e-mail: nadiar@uenf.br

Cite as: Soares, A. C., \& Pereira, N. R. (2020). Drying of jambolão (Syzygium cumini) pulp in spouted bed drier: effect of egg white as drying carrier agent on product quality. Brazilian Journal of Food Technology, 23, e2019075. https://doi.org/10.1590/1981-6723.07519

\begin{abstract}
Resumo
Este trabalho reporta a avaliação da secagem e das propriedades do pó de polpa de jambolão produzido com mistura de maltodextrina 10DE-clara de ovo, em diferentes proporções, como agentes carreadores de secagem (correspondendo a $19,5 \%$ da formulação). A secagem foi realizada em leito de jorro (temperatura do ar de $70^{\circ} \mathrm{C}$, vazão de $2,9 \mathrm{~kg} / \mathrm{min}$ e vazão de alimentação de $11 \mathrm{~g} / \mathrm{min}$ ) com polietileno de baixa densidade como inerte $(550 \mathrm{~g})$, sendo avaliada a influência da composição da mistura de maltodextrina-clara de ovo na eficiência de secagem e nas seguintes propriedades do pó: umidade, atividade de água, diâmetro da partícula, densidade bulk, molhabilidade, solubilidade, higroscopicidade, cor e retenção das antocianinas. Produtos com maior teor de clara de ovo apresentaram maior retenção de antocianinas $(79 \%)$ e menor tempo de molhamento $(6 \mathrm{~min})$ em relação à maltodextrina. Por outro lado, apresentaram redução de $31 \%$ no diâmetro médio e aumento de $35 \%$ na higroscopicidade dos pós, e menor rendimento de produção de pó na secagem (27\%). A densidade bulk aumentou entre $14 \%$ e $19 \%$ após armazenamento por 40 dias, o que pode estar relacionado com alterações nas propriedades físicas do material, principalmente a molhabilidade e a higroscopicidade. Conclui-se que o uso da clara de ovo como agente carreador em combinação com maltodextrina na secagem de jambolão pode ser viável para obtenção de produto em pó com maior retenção de antocianinas e maior teor de proteínas.
\end{abstract}

Palavras-chave: Antocianinas; Jamelão; Maltodextrina; Propriedade física; Desidratação. 


\begin{abstract}
This work evaluates the drying and properties of jambolão pulp powder produced with egg white-maltodextrin 10DE mixture as drying carrier agents, at variable proportions (corresponding to $19.5 \%$ of the formulation mass). The product was dried in a spouted bed dryer (air temperature of $70^{\circ} \mathrm{C}$, air flow of $2.9 \mathrm{~kg} / \mathrm{min}$ and feed flow rate of $11 \mathrm{~g} / \mathrm{min}$ ) using low density polyethylene as inert particles. We assessed the influence of the egg white-maltodextrin mixture composition in the drying recovery and in the powder properties, such as moisture, water activity, particle size, bulk density, wettability, solubility, hygroscopicity, color and anthocyanins retention. Powders produced with higher egg white concentration showed higher anthocyanins retention (79\%) and lower wetting time (6 min) than the ones with higher maltodextrin concentration. Conversely, the former presented reduction of $31 \%$ on mean diameter and increase of $35 \%$ in hygroscopicity of powders and lower dried product recovery (27\%). Bulk densities increased $14 \%$ to $19 \%$ after storage during 40 days. The use of binary egg white-maltodextrin mixture as carrier agent in drying of jambolão pulp is feasible and showed good results for retention of anthocyanins and protein enrichment in the product.
\end{abstract}

Keywords: Anthocyanins; Jambolan; Maltodextrin; Physical property; Dehydration.

\title{
1 Introdução
}

O jambolão (Syzygium cumini), também conhecido como jamelão, jambolana e 'jamun', é considerado uma planta exótica da família Myrtaceae. O fruto é pequeno, de formato ovoide, de coloração roxa quase negra por fora e de polpa carnosa (Vizzoto \& Fetter, 2012), sendo rico em minerais, como fósforo e magnésio, vitamina C, carotenoides, flavonoides, ácido elágico e taninos (Ayyanar \& Subash-Babu, 2012; Mussi et al., 2015; Sharma et al., 2015; Tavares et al., 2016). A presença de antocianinas na composição, principalmente na casca, é responsável por sua coloração característica. As principais antocianinas encontradas no fruto são delphinidina-3,5diglicosídeo, petunidina-3,5-diglicosídeo, malvidina-3,5-diglicosídeo, cyanidina-3,5-diglicosídeo, delphinidina-3, O-glicosídeo e peonidina-3,5-diglicosídeo (Lestario et al., 2017). A rica composição em substâncias fitoquímicas é relacionada à alta atividade antioxidante e a diversas atividades biológicas benéficas à saúde humana (Banerjee et al., 2005; Faria et al., 2011; Singh et al., 2016; Veigas et al., 2007), o que justifica o crescente interesse em pesquisas e utilização de seus produtos.

A secagem em leito de jorro com inertes vem se destacando na secagem de pastas e suspensões (Medeiros et al., 2001). Este método tem sido apresentado como uma alternativa à secagem por spray dryer numa tentativa de obter produtos em pó que sejam de boa qualidade e com baixo custo (Dotto et al., 2011). Tal processo é formado pela atomização da pasta sobre um leito de partículas, que serão revestidas com uma camada fina de material. A película seca se torna frágil e se quebra pelo choque entre as partículas ao longo do processo. O material seco é arrastado para fora da câmara de secagem pela corrente de ar em forma de pó. Em seguida, ocorre a separação do pó por um ciclone conectado ao secador (Freire \& Ferreira, 2009; Medeiros et al., 2001).

$\mathrm{O}$ estudo sobre a secagem de polpas de frutas em leito de jorro e spray drying apresenta defeitos, como produção de pós higroscópicos e características coesivas em razão da presença de açúcares de baixo peso molecular. Diante disso, é necessária a adição de agentes carreadores nas polpas para diminuir adesão do produto, favorecendo o processo de secagem. Em geral, se utilizam carboidratos de alto peso molecular, como maltodextrina, amidos, gomas, pectina e alginato (Araújo, 2014; Coutinho, 2007; Medeiros et al., 2001; Singh et al., 2019; Truong et al., 2005).

$\mathrm{O}$ uso de pequenas quantidades de proteínas em combinação aos carboidratos altera as propriedades superficiais do filme líquido a ser seco, apresentando migração preferencial da proteína na interface ar/água. Maior concentração de proteína na superfície pode promover maior eficiência de secagem e maior retenção de compostos com a vantagem de usar menores quantidades de agentes adjuvantes (Fang \& Bhandari, 2012; Shishir \& Chen, 2017). 
A clara de ovo é uma fonte proteica importante para a alimentação humana. Ela contém 10,5\% de proteína, a qual é composta principalmente de ovoalbumina, ovotransferrina, ovomucoide e lisozima, sendo rica em aminoácidos essenciais (Stevens, 1991). Ela apresenta propriedades emulsificantes, de formação de espuma, formação de gel e capacidade de absorção de água, sendo largamente usada como ingrediente na indústria de alimentos. Na região de Campos dos Goytacazes-RJ, Brasil, ela é descartada como resíduo agroindustrial nas fábricas de chuvisco, doce típico da região. Visando ampliar a utilização de resíduos industriais e agregação de valor à cadeia produtiva regional, a clara de ovo poderia ser utilizada como agente carreador de secagem, visando melhorar o rendimento de secagem e obtenção de polpa seca em pó com incremento nutricional em comparação ao uso de carboidratos para uso como corante alimentício. Outro agente carreador que melhora a eficiência da secagem de pastas em leito de jorro é o dióxido de silício coloidal (Souza et al., 2009).

Portanto, o objetivo deste trabalho foi avaliar a secagem de polpa de jambolão em leito de jorro com inertes para produção de corante alimentício. Foi avaliado o desempenho dos agentes carreadores, maltodextrina e clara de ovo, na secagem, na retenção de antocianinas no produto após a secagem e na estabilidade da cor dos produtos durante armazenamento.

\section{Material e métodos}

\subsection{Polpa de jambolão}

As coletas dos frutos de jambolão maduros foram realizadas em três regiões diferentes da cidade de Campos dos Goytacazes, entre janeiro e maio de 2017. As regiões de coleta dos frutos foram: região A

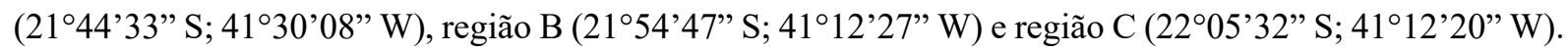
Os frutos foram higienizados, sanitizados (solução de hipoclorito de sódio a $100 \mathrm{mg} / \mathrm{L}$ por 10 minutos) e, posteriormente, despolpados, conforme Mussi et al. (2015). As polpas foram filtradas em tecido sintético com abertura de $48 \mu \mathrm{m}$ e congeladas até o momento das análises.

\subsection{Agentes carreadores}

Os agentes carreadores utilizados foram a maltodextrina Mor-Rex 1910 de 10DE (Ingredion Brasil ingredientes Ltda.), dióxido de silício coloidal (Aerosil ${ }^{\mathbb{2}} 200$ - Pericilglass) e clara de ovo (Doces Tradição). A clara foi pasteurizada a $58^{\circ} \mathrm{C}$ por 2 min e, em seguida, acidificada $(\mathrm{pH} 3,5)$.

\subsection{Caracterização físico-química da pasta e pó}

A análise de umidade foi realizada pelo método gravimétrico 934.06 da AOAC. As cinzas foram determinadas pela incineração da amostra em mufla a $550{ }^{\circ} \mathrm{C}$. O teor de sólidos solúveis totais foi realizado por refratometria pelo método 932.12 e a acidez total titulável, pelo método 33.2.06 da AOAC. O teor de proteína foi obtido pelo método Kjedahl 991.20 da AOAC e os lipídeos, pelo método de Bligh \& Dyer, extração a frio (Association of Official Analytical Chemists, 1998). A determinação do pH foi realizada nas amostras por leitura direta em pHmetro digital. A atividade de água foi determinada a $25^{\circ} \mathrm{C} \mathrm{em}$ medidor de atividade de água (AquaLab DEW - 4TEV, Decagon, USA).

\subsection{Cor instrumental}

A determinação da cor foi realizada em colorímetro portátil (CR-10, Minolta Colour Reader, USA). As amostras foram dispostas em cubeta de vidro, sendo realizadas quatro leituras a cada $90^{\circ}$ perpendicular até atingir $360^{\circ}$ de rotação, totalizando 12 repetições para cada amostra. Os resultados foram obtidos usando 
as coordenadas CIE L*, $\mathrm{a}^{*}$ e $\mathrm{b}^{*}$ (Konica Minolta, 1998) e expressos pelas coordenadas cilíndricas: $C^{*}$ (Equation 1), que define o croma, e $h^{\circ}$ (Equation 2), o ângulo Hue ou ângulo de tonalidade.

$$
\begin{aligned}
& C^{*}=a^{* 2}+b^{* 2} \\
& h^{0}=\arctan \left(\frac{a^{*}}{b^{*}}\right)
\end{aligned}
$$

\subsection{Açúcares}

Os açúcares foram separados, identificados e quantificados por cromatografia líquida de alta eficiência (CLAE), de acordo com Sturm et al. (2003), com algumas modificações. Foram elaborados extratos da polpa e dos pós utilizando água mili-Q na proporção de 1:10 (polpa:água). A extração foi realizada sob agitação por $2 \mathrm{~min}$ em agitador magnético, seguida de ação de ultrassom por $10 \mathrm{~min}$, em banho ultrassônico, e centrifugação a $3.000 \mathrm{rpm}$ durante $10 \mathrm{~min}$. $\mathrm{O}$ extrato foi filtrado em filtro $0,22 \mu \mathrm{m}$ e injetado no cromatógrafo líquido (YL9100, System, YL Instrument Co., Korea) contendo coluna Rezex RCM - Monosaccharide Ca+2 (8\%) (Phenomenex) com água Milli-Q como fase móvel a $0,6 \mathrm{~mL} / \mathrm{min}$ e temperatura da coluna de $40{ }^{\circ} \mathrm{C}$. A realização da curva de calibração foi feita no intervalo de linearidade dos padrões de sacarose, glicose e frutose analisados entre 1 e $4 \mathrm{~g} / \mathrm{L}$, obtendo um coeficiente de correlação $\left(\mathrm{R}^{2}\right)$ de 0,999 .

\subsection{Obtenção dos extratos e avaliação de antocianinas monoméricas totais}

A extração metanólica das polpas e pós foi realizada na concentração de $100 \mathrm{mg} / \mathrm{mL}$ da seguinte maneira: 5 min de agitação, 30 min de ultrassom, 10 min de centrifugação, 24 horas a $4{ }^{\circ} \mathrm{C}$, seguido de 10 min de centrifugação. Após a extração, o sobrenadante foi coletado e utilizado para análise, sem armazenamento prévio. A determinação do conteúdo de antocianina foi realizada pelo método do $\mathrm{pH}$ diferencial, de acordo com Lee et al. (2005), usando espectrofotômetro UV- Visível (105 UV- VIS, Thermo Scientific, Genesys, China) nos comprimentos de onda de 520 e $700 \mathrm{~nm}$.

\subsection{Solubilidade}

A solubilidade da amostra seca foi determinada seguindo o método de Eastman \& Moore (1984), modificado por Cano-Chauca et al. (2005). Amostras em pó e água destilada (1g:100 mL) foram misturadas a $2.500 \mathrm{rpm}$ por 5 minutos e centrifugadas a $3.000 \mathrm{rpm}$ por 5 minutos. Uma alíquota do sobrenadante $(25 \mathrm{~mL})$ foi evaporada em placa de aquecimento e seca em estufa a $105^{\circ} \mathrm{C}$ por 5 horas.

\subsection{Molhabilidade}

A molhabilidade das amostras em pó foi determinada como o tempo necessário para uma amostra em pó ficar totalmente molhada por um líquido. A amostra foi adicionada em um dispositivo descrito por Hogekamp \& Schubert (2003), composto de um cilindro de acrílico, o qual foi preenchido com água destilada, e um compartimento para a amostra de pó, cuja base apresenta uma lâmina munida de um sistema de acionamento por meio elástico. O tempo de molhamento foi considerado até não se observar a presença de material em pó na superfície do líquido.

\subsection{Distribuição de tamanho das partículas}

A distribuição do tamanho das partículas dos pós foi analisada em analisador de tamanho de partículas por difração a laser (SALD-3101, Shimadzu, USA) disponível no Laboratório de Ciências Ambientais (CBB) da UENF. Foi utilizado álcool 95\% como meio líquido com o objetivo de evitar a solubilização do pó. 


\subsection{Densidade bulk solta e empacotada}

A densidade bulk foi medida com auxílio de uma proveta graduada. A densidade bulk solta ( $\rho b s$ ) foi determinada pela massa de partículas, dispostas em arranjo normal, que ocuparam um volume conhecido. A densidade bulk empacotada ( $\rho$ be) foi determinada após compactação, batendo-se a proveta 50 vezes sobre bancada. O índice de Carr foi calculado considerando os valores de densidade bulk solta e empacotada (Equation 3) (Godoi et al., 2010).

$$
I C=100 \times\left(1-\frac{\rho b s}{\rho b e}\right)
$$

\subsection{Higroscopicidade}

A higroscopicidade foi determinada de acordo com Cai \& Corke (2000), com modificações propostas por Tonon, Brabet \& Hubinger (2009). Uma amostra de $1 \mathrm{~g}$ foi acondicionada em dessecador contendo uma solução saturada de $\mathrm{NaCl}$ (umidade relativa de $75,64 \%$ ) a $25^{\circ} \mathrm{C}$. Depois de uma semana, as amostras foram levadas para estufa a $105{ }^{\circ} \mathrm{C}$, até atingir massa constante para determinação de massa seca. A higroscopicidade foi expressa como grama de umidade adsorvida por $100 \mathrm{~g}$ de massa seca da amostra (Equation 4).

Higroscopicidade $(g / 100 \mathrm{~g})=\left(\frac{M s}{\operatorname{Max}(1-X)}\right) \times 100$

em que: Ms = Massa (g) seca após estufa; Ma = Massa (g) de amostra inicial; $\mathrm{X}=$ Umidade do pó (g/g).

\subsection{Processo de secagem em leito de jorro com uso de inertes}

Foi utilizado o secador de leito de jorro cônico-cilíndrico (Figura 1), detalhado em Mussi et al. (2015). $\mathrm{O}$ ar responsável pelo jorro foi alimentado por um compressor radial de $5 \mathrm{CV}$ (CV 501, Ventbras, Brasil) com aquecimento do ar promovido por um conjunto de resistências elétricas e sistema de controle. A vazão do ar foi controlada por uma válvula globo. O produto final (pó) foi coletado em um ciclone tipo Lapple. A pasta, contendo polpa de jambolão e agentes carreadores, foi atomizada na região superior do leito usando um bico atomizador com 0,7 mm de diâmetro de saída (1/4JAU-SS, Spraying Systems), de duplo fluido, alimentado por ar comprimido e pela pasta, usando bomba peristáltica. A distância entre o bico atomizador e a flange superior da parte cônica do leito foi de $250 \mathrm{~mm}$. A velocidade do ar foi medida por um termoanemômetro digital portátil (IP-720, IMPAC, China) posicionado na entrada do tubo do compressor. Os parâmetros fluidodinâmicos analisados foram queda de pressão do jorro e altura da fonte. $\mathrm{O}$ inerte utilizado neste trabalho foi o polietileno de baixa densidade. 


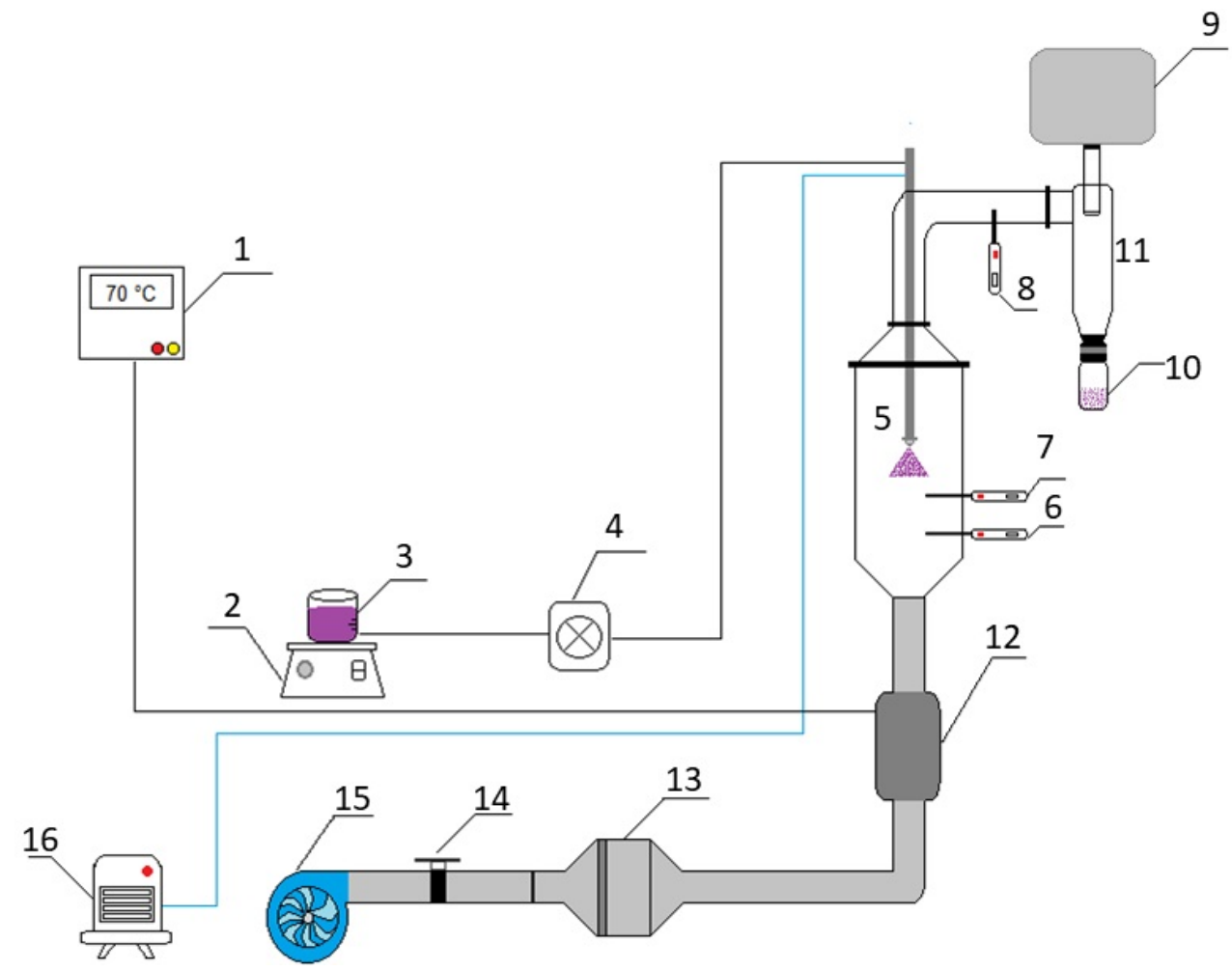

Figura 1. Esquema experimental do leito de jorro com sistema de atomização. (1) painel de controle; (2) agitador magnético; (3) pasta para atomização; (4) bomba peristáltica; (5) peça de atomização; $(6,7,8)$ Termopares;

(9) elutriado (saco); (10) coletor de pó; (11) ciclone; (12) resistência de aquecimento; (13) sistema de resfriamento; (14) válvula globo; (15) compressor radial; (16) compressor (linha de ar comprimido).

\subsection{Condições operacionais}

Os ensaios de secagem foram realizados com vazão do ar fixa com pequenas variações para manutenção da dinâmica estável do sistema. A secagem de $300 \mathrm{~mL}$ de pasta foi realizada em batelada em regime intermitente. Foi definido o tempo de intermitência de 3,5 minutos, sendo 30 segundos com alimentação da pasta no sistema e 3 minutos sem alimentação.

\subsection{Formulações das pastas}

As pastas foram formuladas fixando $80 \%$ da massa de polpa filtrada de jambolão e $20 \%$ de agente carreador, distribuídos em $0,5 \%$ de $\mathrm{SiO}_{2}$ e $19,5 \%$ da mistura contendo maltodextrina e clara de ovo. Foram realizadas três formulações, nomeadas como segue: (75M25C) $75 \%$ de maltodextrina e $25 \%$ de clara em relação aos 19,5\% da composição de adjuvantes na pasta; (50C50M) 50\% de maltodextrina e 50\% de clara em relação aos 19,5\% da composição de adjuvantes na pasta; (25M75C) $25 \%$ de maltodextrina e $75 \%$ de clara em relação aos $19,5 \%$ da composição de adjuvantes na pasta.

\subsection{Rendimento do processo}

O desempenho da secagem em leito de jorro foi avaliado relacionando a massa inicial da pasta com a acumulação de produto no equipamento, inertes e perda por elutriação após o processo de secagem. A porcentagem de rendimento foi calculada individualmente conforme a Equação 5.

Rendimento $(\%)=\left(\frac{(1-X p o ́) \times M p o ́}{(1-X p a) \times M a l}\right) \times 100$ 
em que: Xpó = Umidade do pó coletado no ciclone $(\mathrm{g} / \mathrm{g})$; Mpó = Massa acumulada nas partes do equipamento ou do produto coletado no ciclone $(\mathrm{g}) ; \mathrm{Xpa}=$ Umidade da pasta $(\mathrm{g} / \mathrm{g}) ; \mathrm{Mal}=$ Massa de alimentação (g).

\subsection{Avaliação da estabilidade dos pós à temperatura ambiente}

As amostras foram armazenadas em embalagens herméticas de plástico metalizado, compostas por camada externa de poliéster e interna de polietileno (Tradbor, linha Tradpouch). As amostras embaladas foram armazenadas dentro de um dessecador à temperatura ambiente durante 40 dias. Foram realizadas análises de densidade bulk solta ( $\rho b s$ ), densidade empacotada ( $\rho b e)$ e cor, nos tempos 0 e 40 dias de armazenamento.

\subsection{Análise estatística}

Os dados obtidos neste trabalho foram analisados estatisticamente pelo programa Statistica ${ }^{\circledR}$ versão 7.0, para o teste de comparação de médias, usando análise de variância (ANOVA) e o teste de Tukey em nível de $5 \%$ de significância $(p \leq 0,05)$. Para a realização das análises, as amostras de cada experimento foram analisadas em triplicata.

\section{Resultados e discussão}

\subsection{Caracterização físico-química da polpa de jambolão}

Os resultados na Tabela 1 mostram que a polpa de jambolão é rica em umidade, de $\mathrm{pH}$ ácido e baixo teor de cinzas, lipídios e proteínas. Os resultados estão próximos aos encontrados por Bezerra (2015), Mussi et al. (2015) and Vizzoto \& Fetter (2012).

A polpa filtrada não apresentou diferença significativa $(p>0,05)$ em relação à polpa para as análises de atividade de água, $\mathrm{pH}$, cinzas e lipídios, enquanto que as análises de umidade, sólidos solúveis totais, acidez, proteína e os açúcares sacarose, glicose e frutose apresentaram diferença significativa $(p \leq 0,05)$ quando relacionadas à análise da polpa in natura. Essa diferença pode estar relacionada com a perda de substâncias solúveis na filtração.

Os valores dos parâmetros de cor $L^{*}$ e croma $C^{*}$ da polpa não apresentaram diferença significativa entre as regiões. Apenas o ângulo Hue apresentou diferença entre a região A e C. A luminosidade ( $\left.\mathrm{L}^{*}\right)$ para polpa de jambolão foi próxima à encontrada por Araújo (2014) (11,71) e Bezerra (2015) (11,68), fato este que está relacionado com uma cor mais escura, ou seja, valor mais próximo de zero.

$\mathrm{O}$ croma $\mathrm{C}^{*}$ indica a intensidade da cor e os valores encontrados neste trabalho não apresentaram diferença significativa, bem como indicam que a intensidade se apresenta em uma região mais limpa e menos saturada. Resultados semelhantes foram reportados na literatura (Araújo, 2014; Bezerra, 2015). O ângulo Hue, quando apresenta valores de $0^{\circ}$ ou $360^{\circ}$, indica tonalidade da cor vermelha. Os valores do ângulo hue são próximos aos dados da literatura (Faria et al., 2011), indicando a tonalidade arroxeada. A filtração promoveu redução nos parâmetros de cor em razão da redução do teor de casca do fruto na polpa filtrada.

Com relação aos açúcares, é possível observar que a sacarose foi quantificada em menor quantidade quando relacionada a glicose e frutose. Sturm et al. (2003) reportaram redução do teor de sacarose e aumento dos teores de glicose e frutose com o amadurecimento de diferentes variedades de morango. 
Secagem da polpa de Jambolão (Syzygium cumini) em secador de leito de jorro: efeito da clara de ovo como agente carreador de secagem na qualidade do produto

Soares, A. C., \& Pereira, N. R.

Tabela 1. Caracterização físico-química da polpa pura e da polpa filtrada de jambolão coletadas em diferentes regiões.

\begin{tabular}{|c|c|c|c|c|c|c|}
\hline \multirow[b]{2}{*}{ Análises } & \multicolumn{2}{|c|}{ Região A } & \multicolumn{2}{|c|}{ Região B } & \multicolumn{2}{|c|}{ Região C } \\
\hline & Polpa & $\begin{array}{c}\text { Polpa } \\
\text { filtrada }\end{array}$ & Polpa & $\begin{array}{c}\text { Polpa } \\
\text { filtrada }\end{array}$ & Polpa & $\begin{array}{c}\text { Polpa } \\
\text { filtrada }\end{array}$ \\
\hline Umidade (\%) & $84,0 \pm 0,2^{\mathrm{aA}}$ & $86,0 \pm 0,2^{\mathrm{bA}}$ & $82 \pm 2^{\mathrm{aA}}$ & $90 \pm 0,1^{\mathrm{bB}}$ & $88,0 \pm 0,3^{\mathrm{bA}}$ & $90,5 \pm 0,1^{\mathrm{bB}}$ \\
\hline Aw & $\begin{array}{l}0,986 \pm \\
0,001^{\mathrm{aA}}\end{array}$ & $\begin{array}{c}0,983 \pm \\
0,0005^{\mathrm{bA}}\end{array}$ & $\begin{array}{l}0,9878 \pm \\
0,0009^{\mathrm{aA}}\end{array}$ & $\begin{array}{l}0,9876 \pm \\
0,0008^{\mathrm{aB}}\end{array}$ & $\begin{array}{l}0,985 \pm \\
0,002^{\mathrm{aA}}\end{array}$ & $\begin{array}{l}0,9867 \pm \\
0,0003^{\mathrm{aB}}\end{array}$ \\
\hline pH & $3,7 \pm 0,06^{\mathrm{aA}}$ & $3,6 \pm 0,02^{\mathrm{aA}}$ & $3,34 \pm 0,05^{\mathrm{aB}}$ & $3,46 \pm 0,2^{\mathrm{aA}}$ & $\begin{array}{l}3,18 \pm \\
0,04^{\mathrm{aC}}\end{array}$ & $3,46 \pm 0,07^{\mathrm{bA}}$ \\
\hline SST $\left({ }^{\circ}\right.$ Brix $)$ & $15,2 \pm 0,6^{\mathrm{aA}}$ & $15,6 \pm 0,06^{\mathrm{aA}}$ & $13,5 \pm 1,4^{\mathrm{aAB}}$ & $11,2 \pm 0,06^{\mathrm{bB}}$ & $12,4 \pm 0,5^{\mathrm{aB}}$ & $10,3 \pm 0,3^{\mathrm{aC}}$ \\
\hline Acidez Total (g/100 g) & $8,7 \pm 0,3^{\mathrm{aA}}$ & $7,5 \pm 0,2^{\mathrm{bA}}$ & $9,6 \pm 0,2^{\mathrm{aB}}$ & $7,9 \pm 0,1^{\mathrm{bA}}$ & $10,4 \pm 0,1^{\mathrm{aC}}$ & $8,0 \pm 0,4^{\mathrm{bC}}$ \\
\hline Cinzas $(g / 100 \mathrm{~g})$ & $\begin{array}{l}0,19 \pm \\
0,03^{\mathrm{aA}}\end{array}$ & $0,16 \pm 0,04^{\mathrm{aA}}$ & $0,23 \pm 0,09^{\mathrm{aA}}$ & $\begin{array}{l}0,111 \pm \\
0,007^{\mathrm{aA}}\end{array}$ & $\begin{array}{l}0,18 \pm \\
0,02^{\mathrm{aA}}\end{array}$ & $0,13 \pm 0,04^{\mathrm{aA}}$ \\
\hline Lipídios (g/100 g) & $0,5 \pm 0,5^{\mathrm{aA}}$ & $0,11 \pm 0,05^{\mathrm{aA}}$ & $0,3 \pm 0,1^{\mathrm{aA}}$ & $0,10 \pm 0,1^{\mathrm{aA}}$ & $0,2 \pm 0,1^{\mathrm{aA}}$ & $0,13 \pm 0,01^{\mathrm{aA}}$ \\
\hline Proteínas (g/100 g) & $0,7 \pm 0,1^{\mathrm{aA}}$ & $0,36 \pm 0,03^{\mathrm{aB}}$ & $0,8 \pm 0,1^{\mathrm{aA}}$ & $0,28 \pm 0,05^{\mathrm{aB}}$ & $\begin{array}{l}0,57 \pm \\
0,05^{\mathrm{aA}}\end{array}$ & $0,34 \pm 0,04^{\mathrm{aB}}$ \\
\hline $\begin{array}{c}\text { Carboidratos totais } \\
(\mathrm{g} / 100 \mathrm{~g})^{1}\end{array}$ & $14,6 \pm 0,6$ & $13,4 \pm 0,2$ & $16 \pm 2$ & $9,2 \pm 0,2$ & $11,0 \pm 0,3$ & $8,9 \pm 0,2$ \\
\hline Sacarose $(\mathrm{mg} / \mathrm{g})$ & $29 \pm 1^{\mathrm{aA}}$ & $24,3 \pm 0,4^{\mathrm{aB}}$ & $34 \pm 3^{\mathrm{aA}}$ & $28 \pm 1^{\mathrm{bB}}$ & $33 \pm 1^{\mathrm{a}} \mathrm{A}$ & $24 \pm 1^{\mathrm{aB}}$ \\
\hline Glicose (mg/g) & $335 \pm 13^{\mathrm{aA}}$ & $330 \pm 2^{\mathrm{aA}}$ & $316 \pm 17^{\mathrm{aA}}$ & $264 \pm 15^{\mathrm{bB}}$ & $318 \pm 18^{\mathrm{aA}}$ & $239 \pm 9^{\mathrm{bB}}$ \\
\hline Frutose (mg/g) & $369 \pm 24^{\mathrm{aA}}$ & $348 \pm 2^{\mathrm{aA}}$ & $336 \pm 19^{\mathrm{aA}}$ & $282 \pm 17^{\mathrm{bB}}$ & $336 \pm 18^{\mathrm{aA}}$ & $253 \pm 9^{\mathrm{bB}}$ \\
\hline $\begin{array}{l}\text { Antocianinas } \\
(\mathrm{mg} / 100 \mathrm{~g})^{2}\end{array}$ & $659 \pm 88^{\mathrm{aA}}$ & $598 \pm 88^{\mathrm{aA}}$ & $497 \pm 63^{\mathrm{aA}}$ & $353 \pm 5^{\mathrm{aB}}$ & $594 \pm 19^{\mathrm{aA}}$ & $451 \pm 26^{\mathrm{aA}}$ \\
\hline \multicolumn{7}{|l|}{ Cor } \\
\hline Parâmetro $L^{*}$ & $15,0 \pm 0,3^{\mathrm{aA}}$ & $7,62 \pm 0,25^{\mathrm{aB}}$ & $\begin{array}{c}18,56 \pm \\
0,03^{\mathrm{aA}}\end{array}$ & $9,6 \pm 0,3^{\mathrm{bB}}$ & $15,7 \pm 0,2^{\mathrm{aA}}$ & $\begin{array}{c}12,86 \pm \\
1,01^{\mathrm{cB}}\end{array}$ \\
\hline Croma C* & $28,6 \pm 0,3^{\mathrm{aA}}$ & $6,35 \pm 0,67^{\mathrm{aB}}$ & $\begin{array}{c}33,35 \pm \\
0,06^{\text {aA }}\end{array}$ & $17 \pm 1^{\mathrm{aB}}$ & $32,4 \pm 0,1^{\mathrm{aA}}$ & $19,2 \pm 0,5^{\mathrm{bB}}$ \\
\hline Ângulo Hue* & $\begin{array}{c}340,2 \pm \\
0,4^{\mathrm{aA}}\end{array}$ & $346,3 \pm 1,6^{\mathrm{aB}}$ & $341,0 \pm 0,1^{\mathrm{abA}}$ & $329 \pm 2^{\mathrm{aB}}$ & $\begin{array}{c}341,5 \pm \\
0,5^{\mathrm{bA}}\end{array}$ & $327,5 \pm 3,6^{\mathrm{bB}}$ \\
\hline
\end{tabular}

Valores médios \pm desvio padrão. Valores na mesma linha seguidos de mesma letra minúscula não diferem significativamente $(p>0,05)$ comparando regiões $\mathrm{A}, \mathrm{B}$ e C, e valores seguidos de letra maiúscula não diferem significativamente comparando polpa e polpa filtrada. Região

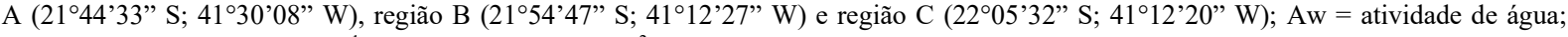
SST $=$ teor de sólidos solúveis. ${ }^{1}$ Calculado por diferença. ${ }^{2}$ Expresso em base seca.

A polpa pura e a polpa filtrada não apresentaram variações no teor de antocianinas entre si e nem entre as diferentes regiões das coletas $(p>0,05)$ (Tabela 1). O teor de antocianinas encontrado no presente estudo está superior ao encontrado por Veigas et al. (2007) [230 mg/ 100g (base seca)] utilizando extrato metanol acidificado (1\%) e inferior a Araújo (2014) [720,9 mg/100g (base seca)] utilizando extrato aquoso. Essas variações podem ser decorrentes do método de extração e as características da região, como cultivo/crescimento, clima e solo da região de coletas dos frutos, o que pode interferir diretamente na composição do próprio fruto e na quantificação dos compostos. Outro fator que pode influenciar são as diferentes adaptações feitas na metodologia.

\subsection{Fluidodinâmica do material inerte polietileno de baixa densidade}

De acordo com a curva fluidodinâmica do inerte (Figura 2), as partículas apresentaram aumento da queda de pressão no leito e uma pequena elevação do leito com o aumento da velocidade do ar. Verificou-se o desenvolvimento do jorro mínimo das partículas em velocidade de $13 \mathrm{~m} / \mathrm{s}$. Foi observado um jorro intenso e elutriação dos inertes para o ciclone em velocidades próximas de $20 \mathrm{~m} / \mathrm{s}$. Altas velocidades possuem maior gasto de energia e o material se encontra na região de arraste. Ao atomizar a pasta sobre o leito de partículas inertes, foi observado que, com velocidades abaixo de $22 \mathrm{~m} / \mathrm{s}$, não era possível obter um jorro estável e, com isso, acarretou em um colapso no leito. A velocidade de jorro mínimo $(13 \mathrm{~m} / \mathrm{s})$, que corresponde a uma vazão de $1,96 \mathrm{~kg} / \mathrm{min}$, utilizada neste trabalho, é alta quando comparada a outros trabalhos, mas este comportamento 
pode ser explicado pelas próprias condições de construção do equipamento. Braga (2014) reportou vazões de jorro mínimo iguais a 0,87 e $0,86 \mathrm{~kg} / \mathrm{min}$ para polipropileno e polietileno de baixa densidade, respectivamente.

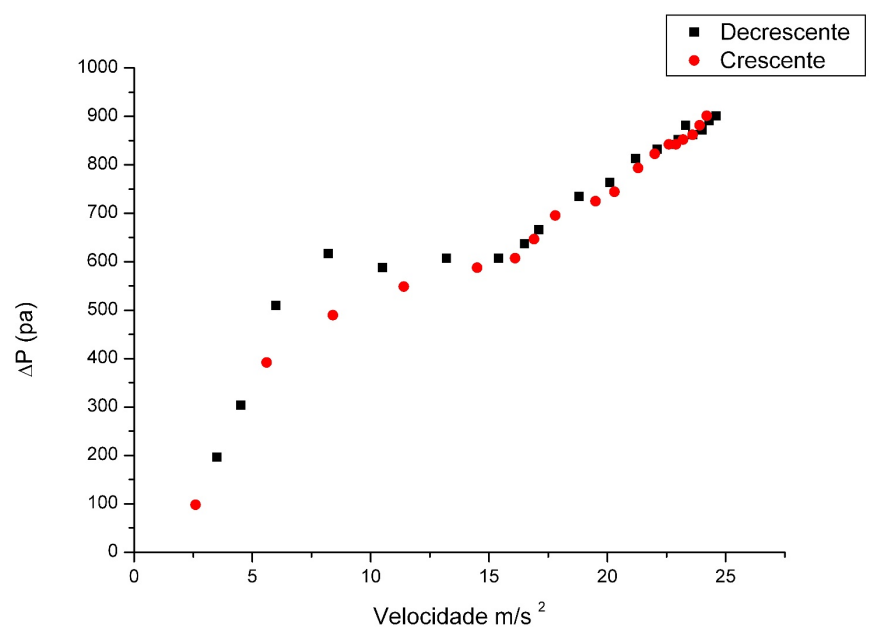

Figura 2. Curva fluidodinâmica do material inerte PEBD avaliando a queda de pressão $(\Delta \mathrm{P})$ no leito de jorro em função da velocidade do ar crescente e decrescente.

\subsection{Efeito da mistura clara acidificada e maltodextrina DE10}

A umidade do pó após a secagem foi influenciada pela concentração de adjuvantes na pasta $(p \leq 0,05)$ (Tabela 2). A amostra 75M25C apresentou menor umidade e a amostra 25M75C, a maior umidade. No entanto, a atividade de água das amostras não diferiu estatisticamente $(p>0,05)$. Os valores encontrados, 0,25 a 0,26, são inferiores aos de pós de jambolão-goma arábica de 0,35 (Araújo, 2014). A acidez e o teor de proteína do pó aumentaram proporcionalmente com o aumento da clara na composição do pó, em razão da adição de clara acidificada em substituição parcial da maltodextrina na pasta formulada. Uma porção de uma colher de sopa de pó $(5,5 \mathrm{~g})$ da amostra 25M75C representa $0,6 \%$ da ingestão diária de proteína recomentada para adultos e 0,9\% para crianças de 7 a 10 anos (Brasil, 2005).

Tabela 2. Caracterização físico-química do pó de jambolão produzido em leito de jorro com diferentes concentrações de agentes carreadores.

\begin{tabular}{|c|c|c|c|}
\hline Análises & $75 \mathrm{M} 25 \mathrm{C}$ & 50M50C & 25M75C \\
\hline Umidade $(\mathrm{g} / 100 \mathrm{~g})$ & $6,7 \pm 0,7^{\mathrm{a}}$ & $8 \pm 1^{\mathrm{b}}$ & $12 \pm 1^{\mathrm{c}}$ \\
\hline Aw & $0,25 \pm 0,04^{\mathrm{a}}$ & $0,26 \pm 0,04^{\mathrm{a}}$ & $0,26 \pm 0,03^{\mathrm{a}}$ \\
\hline Acidez Total (g/100 g) & $2,3 \pm 0,2^{\mathrm{a}}$ & $3,86 \pm 0,07^{\mathrm{b}}$ & $5,95 \pm 0,08^{\mathrm{c}}$ \\
\hline Proteína $(\mathrm{g} / 100 \mathrm{~g})$ & $2,7 \pm 0,5^{\mathrm{a}}$ & $4,87 \pm 0,06^{\mathrm{b}}$ & $5,3 \pm 0,4^{\mathrm{c}}$ \\
\hline Antocianinas $(\mathrm{mg} / 100 \mathrm{~g})^{1}$ & $74 \pm 12^{\mathrm{a}}$ & $115 \pm 6^{\mathrm{b}}$ & $164 \pm 19^{c}$ \\
\hline Retenção Antocianinas (\%) & 55 & 66 & 79 \\
\hline$\rho_{\text {bulk-s }}\left(\mathrm{g} / \mathrm{cm}^{3}\right)$ & $0,35 \pm 0,01^{\mathrm{b}}$ & $0,38 \pm 0,01^{\mathrm{a}}$ & $0,36 \pm 0,00^{\mathrm{a}}$ \\
\hline Pbulk-e $\left(\mathrm{g} / \mathrm{cm}^{3}\right)$ & $0,55 \pm 0,01^{\mathrm{a}}$ & $0,52 \pm 0,01^{\mathrm{a}}$ & $0,52 \pm 0,02^{\mathrm{a}}$ \\
\hline Índice de Carr (\%) & $36,8 \pm 0,5^{\mathrm{a}}$ & $27 \pm 2^{\mathrm{b}}$ & $29 \pm 3^{\mathrm{ab}}$ \\
\hline Solubilidade $(\mathrm{g} / 100 \mathrm{~g})$ & $80 \pm 13^{\mathrm{a}}$ & $82 \pm 5^{\mathrm{a}}$ & $83 \pm 4^{a}$ \\
\hline Tempo de molhamento (min) & $10 \pm 1^{\mathrm{a}}$ & $8,4 \pm 0,5^{b}$ & $6 \pm 0,5^{\mathrm{c}}$ \\
\hline Higroscopicidade $(\mathrm{g} / 100 \mathrm{~g})$ & $19,2 \pm 0,5^{\mathrm{a}}$ & $19,8 \pm 0,8^{\mathrm{a}}$ & $26 \pm 2^{\mathrm{b}}$ \\
\hline Diâmetro médio $(\mu \mathrm{m})$ & $11,4 \pm 0,6^{\mathrm{a}}$ & $13,3 \pm 0,4^{\mathrm{b}}$ & $7,88 \pm 0,06^{\mathrm{c}}$ \\
\hline \multicolumn{4}{|l|}{ Cor } \\
\hline $\mathrm{L}^{*}$ & $73,65 \pm 0,08^{a}$ & $70,9 \pm 0,1^{\mathrm{b}}$ & $67,51 \pm 0,05^{\mathrm{c}}$ \\
\hline Croma C* & $19,0 \pm 0,2^{\mathrm{a}}$ & $21,21 \pm 0,03^{b}$ & $23,87 \pm 0,08^{\mathrm{c}}$ \\
\hline Ângulo Hue $\mathrm{h}^{\circ}$ & $323,0 \pm 0,5^{\mathrm{a}}$ & $326,7 \pm 0,5^{\mathrm{b}}$ & $329,3 \pm 0,3^{\mathrm{c}}$ \\
\hline
\end{tabular}

Valores médios \pm desvio padrão. Valores na mesma linha seguidos de letras iguais não diferem significativamente $(p>0,05)$. Aw $=$ atividade de água; $\rho_{\text {bulk-s }}=$ densidade bulk solta; $\rho_{\text {bulk-e }}$ densidade bulk empacotada. ${ }^{1}$ Expresso em base seca. 
Os teores de antocianinas apresentaram diferença estatística entre as amostras. As concentrações de antocianina dos pós com maior quantidade de clara acidificada foram superiores em comparação ao pó com maior concentração de maltodextrina, mostrando o efeito protetor da clara em relação às antocianinas. A retenção de antocianinas do pó seco em relação à pasta aumenta de 54\% (amostra 75M25C) para 79\% (amostra 25M75C) com o aumento de 25\% para 75\% de clara na composição dos agentes carreadores na pasta. Tonon et al. (2009) avaliaram a secagem de açaí por spray dryer em diferentes concentrações de maltodextrina e observaram que o uso de concentrações menores do agente carreador poderia resultar em produtos com maior teor de antocianinas (menos "diluídos").

Todos os parâmetros de cor avaliados apresentaram diferença significativa entre as amostras (Tabela 2). O parâmetro de luminosidade L* é maior para amostra 75M25C, o que está relacionado com adição do agente carreador maltodextrina. que apresenta coloração clara e influencia diretamente no material obtido após o processo de secagem. Quanto menor a concentração deste agente carreador, menor o parâmetro L*, o que é observado nas amostras 50M50C e 25M75C (Figura 3). O aumento da concentração de clara acidificada nas amostras aumentou o valor do parâmetro croma $C^{*}$, maior é a intensidade da cor. Araújo (2014) reportou valor de 16,25, valor inferior ao encontrado neste estudo. Os pós obtidos possuem valores do ângulo Hue de 323 a $329^{\circ}$, valores que representam a tonalidade roxa avermelhada. As amostras com maior concentração de clara apresentaram maior valor de ângulo Hue, o que indica a maior concentração de antocianinas, quando comparada à amostra com maior concentração de maltodextrina. Araújo (2014) encontrou valores superiores avaliando este parâmetro $\left(359,73^{\circ}\right)$.

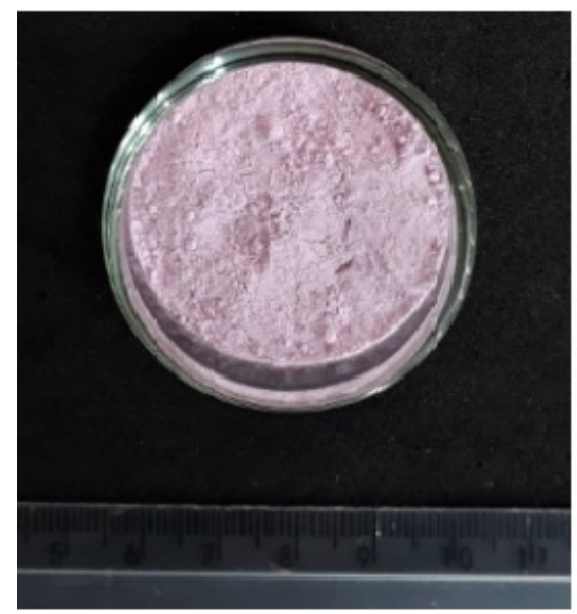

$75 \mathrm{M} 25 \mathrm{C}$

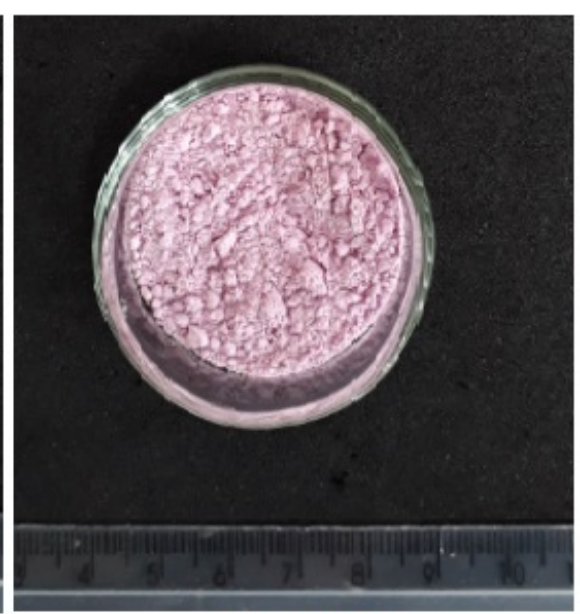

50M 50C

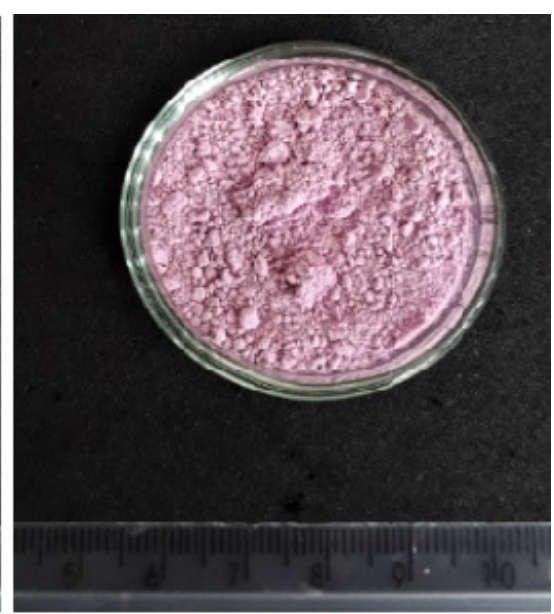

$25 \mathrm{M} 75 \mathrm{C}$

Figura 3. Fotografias do pó obtido no processo de secagem com diferentes concentrações de agente carreador maltodextrina e clara acidificada.

A Tabela 2 apresenta os dados de caracterização física dos pós de jambolão. A pbs das amostras variou entre 0,347 e $0,391 \mathrm{~g} / \mathrm{cm}^{3}$. Esse intervalo está próximo aos encontrados na literatura para mirtilo em pó (Darniadi et al., 2018). A amostra 75M25C apresentou maior $\rho b s$ em relação às demais $(p \leq 0,05)$. A $\rho b s$ considera os poros internos assim como os espaços vazios entre partículas, já a pbe desconsidera todos os espaços vazios. Com o empacotamento, os valores de pbe aumentaram e não apresentaram diferença estatística entre si $(p>0,05)$. Todas as amostras apresentaram baixa escoabilidade com IC > 28\% (Turchiuli et al., 2005). O índice de Carr da amostra 75M25C foi superior aos das demais amostras, indicando escoamento muito coesivo. Com o aumento de clara na pasta, as amostras secas passaram a ter escoamento coesivo. 
A solubilidade das amostras não diferiu estatisticamente e seus valores se encontraram próximos aos encontrados para pó de jambolão-goma arábica de 81,6\% (Araújo, 2014) e de clara de ovo de $80 \%$ (Christ, 2006), ambos secos em leito de jorro com inertes, e de jambolão-maltodextrina seco por spray drying de $80 \%$ a 93\% (Singh et al., 2019). Amostras com maior concentração de clara apresentaram formação de aglomerados (Figura 3) e maior higroscopicidade. A substituição de $75 \%$ de maltodextrina por clara na formulação da pasta promoveu um incremento de 35\% na umidade higroscópica do pó. O diâmetro médio das partículas, por sua vez, diminuiu com o aumento da concentração de clara na pasta $(p \leq 0,05)$. As partículas apresentaram diâmetro médio entre 11,4 e 7,88 $\mu \mathrm{m}$, mesma ordem de grandeza do pó de açaí-maltodextrina seco por atomização (Tonon et al., 2009). O tempo de molhamento dos pós variou entre 6 e 10 min, havendo uma tendência linear $\left(\mathrm{R}^{2}=0,97\right)$ de redução do tempo com o aumento da concentração de clara na formulação da pasta. Os valores obtidos estão próximos aos encontrados por Tonon et al. (2009) de 8,61 min para pó de açaí-maltodextrina obtido por secagem por atomização. Maior higroscopicidade, formação de aglomerados e menor diâmetro favorecem a molhabilidade dos produtos em pó (Hogekamp \& Schubert, 2003).

A Figura 4 apresenta o rendimento dos pós obtidos a partir de pastas com diferentes concentrações de agentes carreadores. O rendimento de produção de pó variou entre 5 e 35\%. Esses valores são próximos aos encontrados por Braga (2014) para secagem de leite-polpa de amora-preta em leito de jorro usando PEBD como inerte, e inferiores ao encontrado por Araújo (2014) para secagem de polpa de jambolão-goma arábica em leito de jorro usando PEAD como inerte (62\%). O rendimento de produção de pós em leito de jorro é influenciado pelas características físicas dos inertes e pela relação de adesão inerte-pasta, além da vazão de alimentação, massa de inerte e temperatura e vazão do ar (Medeiros et al., 2001; Rocha \& Taranto, 2008). Braga (2014) obteve rendimento de produção de pó de leite-polpa de amora-preta de $63,2 \%$ usando poliestireno (PS) como inerte, 25,5\% para polietileno de baixa densidade (PEBD) e 22,3\% para o polietileno de alta densidade (PEAD). Portanto, estudos posteriores são necessários para verificar a influência da natureza do inerte no rendimento, visando à otimização do processo.

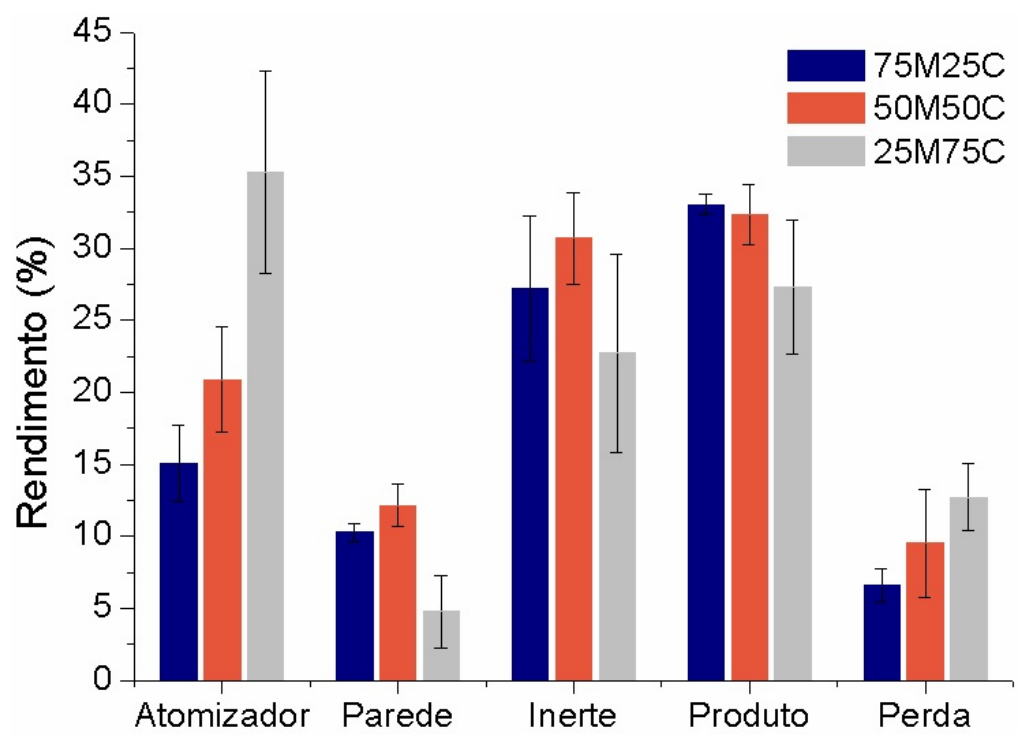

Figura 4. Rendimento de pó no produto final e nas peças do equipamento leito de jorro para diferentes proporções de maltodextrina e clara de ovo como agentes carreadores.

Com relação à formulação, foi observado um decréscimo do rendimento do produto com o aumento da concentração de clara na pasta. A pasta com formulação 25M75C apresentou $17 \mathrm{~g} / 100 \mathrm{~g}$ de sólidos enquanto a formulação $75 \mathrm{C} 25 \mathrm{M}$ apresentou $26 \mathrm{~g} / 100 \mathrm{~g}$ de sólidos, representando $11 \%$ a mais de umidade para ser 
removida na secagem. Isso promoveu maior saturação do ar na câmara de secagem na formulação com maior concentração de clara de ovo, contribuindo para baixo rendimento de produção de pó e maior retenção nas partes do equipamento. Essa maior retenção foi mais evidente na tubulação do sistema de atomização, região mais úmida da câmara de secagem. Maior higroscopicidade e menor diâmetro da amostra 25M75C (mais rica em proteína) favorecem essa maior retenção nas partes do equipamento. A viscosidade aparente das

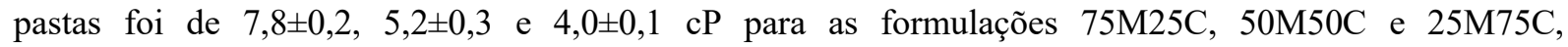
respectivamente. Essa redução pode ser consequência do efeito de diluição promovido pela substituição da maltodextrina em pó pela clara. A redução da viscosidade de pastas aumenta a área de filme líquido superficial formado, sendo mais favorável à formação de pontes líquidas de adesão (partes do equipamento/produto) e de coesão (produto/produto), resultando em incremento no acúmulo de material sobre inerte e nas paredes e partes do equipamento (Souza et al., 2009).

\subsubsection{Estabilidade do produto}

A estabilidade da cor de produtos em pó tem importante papel na aparência dos produtos e também é um indicativo das reações de degradação dos nutrientes e substâncias bioativas. A luminosidade $\left(\mathrm{L}^{*}\right)$ das amostras com mais de $50 \%$ de clara de ovo na mistura de adjuvantes (50M50C e 25M75C) reduziu após o armazenamento $(p \leq 0,05)$ (Figura 5). Contrariamente, a amostra 75M25C apresentou aumento no parâmetro $L^{*}$. No entanto, as variações nesse parâmetro foram inferiores a 2,3\%. O croma $C^{*}$ apresentou redução significativa $(p \leq 0,05)$ entre 4,2 e $4,8 \%$ para todas as amostras, indicando redução na saturação da cor. O ângulo Hue apresentou aumento inferior a $1,2 \%$ para todas as amostras $(p \leq 0,05)$ após o armazenamento e indica deslocamento da tonalidade roxa em direção ao vermelho (consequência da redução do parâmetro b, que indica cor azul). Essas alterações podem ter efeito pouco significativo em aplicações práticas, mas são indicativos de reações de alteração dos produtos e redução de antocianinas.

Alterações de cor durante armazenamento também foram observadas durante armazenamento de antocianinas secas por atomização com e sem maltodextrina como adjuvante de secagem (Weber et al., 2017) e em extrato aquoso de jambolão (Veigas et al., 2007). Essas alterações na cor dos produtos durante o armazenamento podem estar relacionadas com degradação de antocianinas por reações de condensação e oxidação de antocianinas e outras substâncias fenólicas (Sinela et al., 2017; Weber et al., 2017).

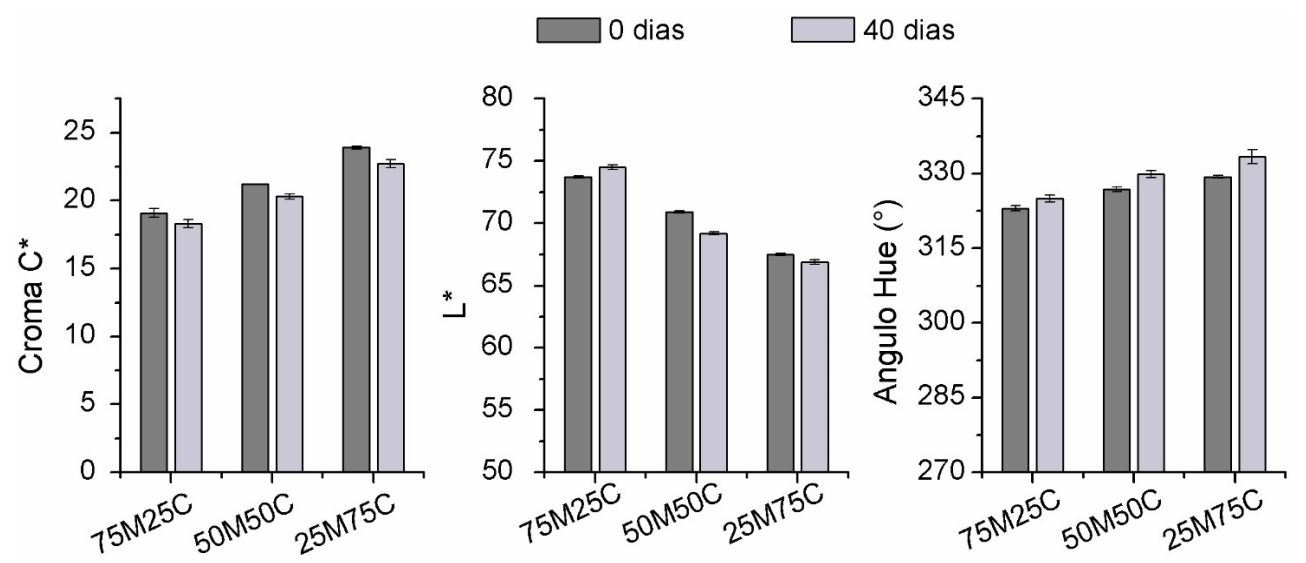

Figura 5. Estabilidade da cor do pó de jambolão após armazenamento para diferentes proporções de maltodextrina e clara de ovo como agentes carreadores.

Para as análises de $\rho b s$ e $\rho b e$, foram observadas variações entre as amostras avaliadas. A $\rho b s$ das amostras $75 \mathrm{M} 25 \mathrm{C}$ e $25 \mathrm{M} 75 \mathrm{C}$ aumentou durante o armazenamento de 40 dias (Figura 6). Esse aumento pode alterar as propriedades físicas do material, principalmente a molhabilidade e a higroscopicidade do pó. Densidade 
maior tende a deixar os pós mais pesados e aglomerados, comportamento que afeta a qualidade e a vida útil do produto. A pbe apresentou estabilidade durante o tempo de armazenamento para todas as amostras.
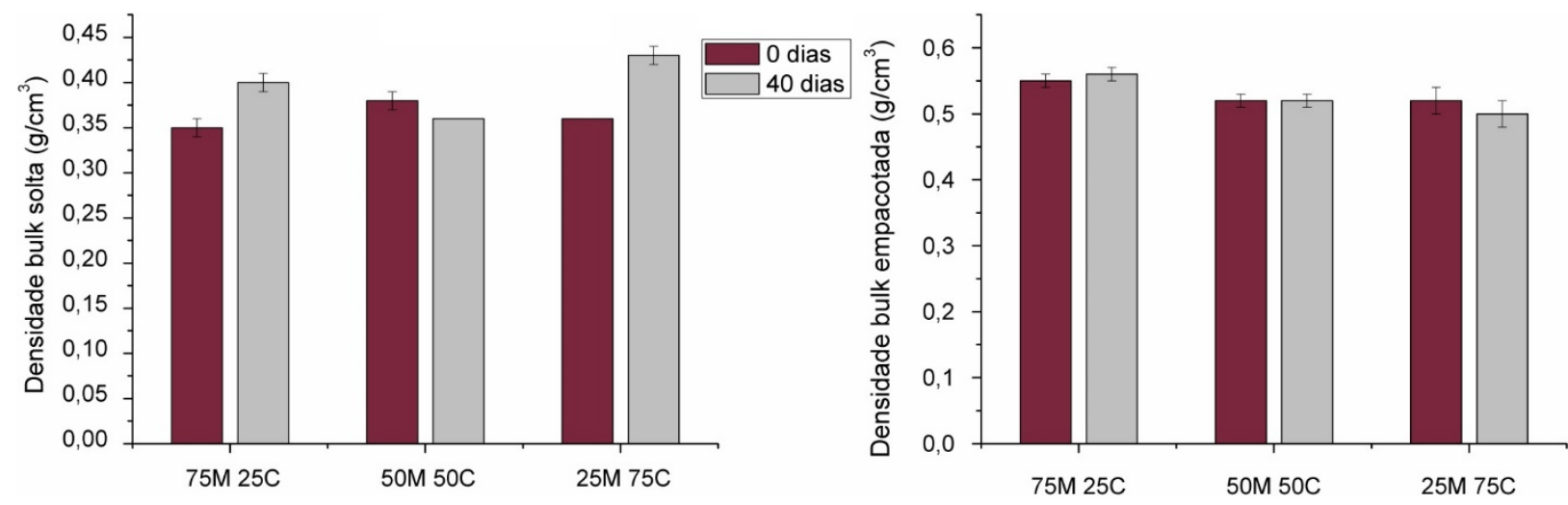

Figura 6. Densidade bulk solta e empacotada do pó de jambolão após armazenamento para diferentes proporções de maltodextrina e clara de ovo como agentes carreadores.

\section{Conclusão}

A mistura de maltodextrina e clara como adjuvantes de secagem é uma tecnologia interessante para produção de pó de jambolão rico em antocianinas e com maior teor de proteína. Maiores quantidades de clara na mistura resultaram em pó com maior teor de proteínas e antocianinas totais, e maior retenção das antocianinas após o processo de secagem. Por outro lado, o aumento na concentração de clara resultou em menor rendimento de produção de pó, menor diâmetro médio das partículas, maior higroscopicidade e menor tempo de molhamento, quando comparado às demais amostras. $\mathrm{O}$ armazenamento por 40 dias promoveu suave alteração da cor, não havendo efeito da formulação da pasta na estabilidade da cor dos produtos.

\section{Agradecimentos}

Os autores agradecem à Coordenação de Aperfeiçoamento de Pessoal de Nível Superior (CAPES) pela bolsa de estudo associada a este trabalho, assim como à Fundação Carlos Chagas Filho de Amparo à Pesquisa do Estado do Rio de Janeiro (FAPERJ) (processo n. ${ }^{\circ}$ E26/202.858/2015), à CAPES (processo n. ${ }^{\circ}$ 001) e à UENF, pelo apoio financeiro.

\section{Referências}

Araújo, A. L. M. (2014). Polpa de jambolão (Syzygium cumini) desidratada por liofilização e secagem em leito de jorro: Caracterização físico-quimica e funcional e impacto da secagem (Dissertação de mestrado). Universidade Federal do Rio Grande do Norte, Natal.

Association of Official Analytical Chemists - AOAC. (1998). Official methods of analysis. Washington: AOAC.

Ayyanar, M., \& Subash-Babu, P. (2012). Syzygium cumini (L.) skeels: A review of its phytochemical constituents and traditional uses. Asian Pacific Journal of Tropical Biomedicine, 2(3), 240-246. PMid:23569906. http://dx.doi.org/10.1016/S22211691(12)60050-1

Banerjee, A., Dasgupta, N., \& De, B. (2005). In vitro study of antioxidant activity of Syzygium cumini fruit. Food Chemistry, 90(4), 727-733. http://dx.doi.org/10.1016/j.foodchem.2004.04.033

Bezerra, M. F. (2015). Polpa de jambolão (Eugenia jambolana Lam.) fresca e desidratada: Características físico-químicas, bioativas e funcionais, efeitos biológicos em Caenorhabditis elegans e uso para produção de frozen yogurt caprino probiótico (Tese de doutorado). Universidade Federal do Rio Grande do Norte, Natal.

Braga, M. B. (2014). Obtenção de mistura leite-amora preta em pó por secagem em leito de jorro (Tese de doutorado). Universidade Estadual de Campinas, Campinas.

Brasil. Ministério da Saúde. Agência Nacional de Vigilância Sanitária - ANVISA. (2005, setembro 23). RDC nº 269. Regulamento técnico sobre a Ingestão Diária Recomendada (IDR) de proteína, vitaminas e minerais. Diário Oficial da União, 
Brasília. Retrieved in 2012, July 5, from http://portal.anvisa.gov.br/documents/33916/394219/RDC_269_2005.pdf/2e95553ca482-45c3-bdd1-f96162d607b3

Cai, Y. Z., \& Corke, H. (2000). Production and properties of spray-dried Amaranthus betacyanin pigments. Journal of Food Science, 65(7), 1248-1252. http://dx.doi.org/10.1111/j.1365-2621.2000.tb10273.x

Cano-Chauca, M., Stringheta, P. C., Ramos, A. M., \& Cal-Vidal, J. (2005). Effect of the carriers on the microstructure of mango powder obtained by spray drying and its functional characterization. Innovative Food Science \& Emerging Technologies, 6(4), 420-428. http://dx.doi.org/10.1016/j.ifset.2005.05.003

Christ, D. (2006). Secagem de clara de ovo em leito de jorro fluidizado bidimensional (Tese de doutorado). Universidade Estadual de Campinas, Campinas.

Coutinho, A. (2007). Produção e caracterização de maltodextrinas a partir de amidos de mandioca e batata-doce (Tese de doutorado). Universidade Estadual Paulista “Júlio de Mesquita Filho", Botucatu.

Darniadi, S., Ho, P., \& Murray, B. S. (2018). Comparison of blueberry powder produced via foam-mat freeze-drying versus spray-drying: Evaluation of foam and powder properties. Journal of the Science of Food and Agriculture, 98(5), 2002-2010. PMid:28940205. http://dx.doi.org/10.1002/jsfa.8685

Dotto, G. L., Souza, V. C., \& Pinto, L. A. A. (2011). Drying of chitosan in a spouted bed: The influences of temperature and equipment geometry in powder quality. Lebensmittel-Wissenschaft + Technologie, 44(8), 1786-1792. http://dx.doi.org/10.1016/j.Iwt.2011.03.019

Eastman, J., \& Moore, C. (1984). Cold-water-soluble granular starch for gelled food compositions. US Patent 4,465,702. Alexandria: United States Patent and Trademark Office.

Fang, Z., \& Bhandari, B. (2012). Comparing the efficiency of protein and maltodextrin on spray drying of bayberry juice. Food Research International, 48(2), 478-483. http://dx.doi.org/10.1016/j.foodres.2012.05.025

Faria, A. F., Marques, M. C., \& Mercadante, A. Z. (2011). Identification of bioactive compounds from jambolão (Syzygium cumini) and antioxidant capacity evaluation in different pH conditions. Food Chemistry, 126(4), 1571-1578. PMid:25213929. http://dx.doi.org/10.1016/j.foodchem.2010.12.007

Freire, J. T., \& Ferreira, M. C. (2009). Aplicações em sistemas particulados. São Carlos: Departamento de Engenharia Química, Universidade Federal de São Carlos.

Godoi, F. C., Boin, E. S. F., Pereira, N. R., \& Rocha, S. C. S. (2010). Fluid dynamics and drying of cohesive particles of a biodegradable polymer (poly-hydroxybutyrate) in a rotating pulsed fluidized bed. Drying Technology, 28(11), 1297-1306. http://dx.doi.org/10.1080/07373937.2010.487715

Hogekamp, S., \& Schubert, H. (2003). Rehydration of food powders theoretical aspects of wetting and dispersing of powders. Food Science \& Technology International, 9(3), 223-235. http://dx.doi.org/10.1177/1082013203034938

Konica Minolta. (1998). Comunicação precisa da cor: Controle de qualidade da percepção à instrumentação. Seoul: Konica Minolta. Retrieved in 2011, February 15, from www.konicaminolta.com/sensingusa/support/product_applications

Lee, J., Durst, R. W., \& Wrolstad, R. E. (2005). Determination of total monomeric anthocyanin pigment content of fruit juices, beverages, natural colorants, and wines by the $\mathrm{pH}$ differential method: Collaborative study. Journal of AOAC International, 88(5), 1269-1278. PMid:16385975. http://dx.doi.org/10.1093/jaoac/88.5.1269

Lestario, L. N., Howard, L. R., Brownmiller, C., Stebbins, N. B., Liyanage, R., \& Lay, J. O. (2017). Changes in polyphenolics during maturation of Java plum (Syzygium cumini Lam.). Food Research International, 100, 385-391. PMid:28964361. http://dx.doi.org/10.1016/j.foodres.2017.04.023

Medeiros, M. F. D., Alsina, O. L. S., Rocha, S. C., Jerônimo, C. E. M., Mata, A. L. M. L., Medeiros, U. K. L., \& Furtunato, A. A. (2001). Escoabilidade de leitos de partículas inertes com polpa de frutas tropicais: Efeitos na secagem em leito de jorro. Revista Brasileira de Engenharia Agrícola e Ambiental, 5(3), 475-480. http://dx.doi.org/10.1590/S1415-43662001000300018

Mussi, L. P., Guimarães, A. O., Ferreira, K. S., \& Pereira, N. R. (2015). Spouted bed drying of jambolão (Syzygium cumini) residue: Drying kinetics and effect on the antioxidant activity, anthocyanins and nutrients contents. Lebensmittel-Wissenschaft + Technologie, 61(1), 80-88. http://dx.doi.org/10.1016/j.Iwt.2014.11.040

Rocha, S. C. S., \& Taranto, O. P. (2008). Advances in spouted bed drying of foods. In C. Ratti (Ed.), Advances in food dehydration (pp. 204). Boca Raton: CRC Press.

Sharma, R. J., Gupta, R. C., Bansal, A. K., \& Singh, I. P. (2015). Metabolite fingerprinting of eugenia jambolana fruit pulp extracts using NMR, HPLC-PDA-MS, GC-MS, MALDI-TOF-MS and ESI-MS/MS spectrometry ram. Natural Product Communications, 10(6), 969-976. PMid:26197529. http://dx.doi.org/10.1177/1934578X1501000644

Shishir, M. R. I., \& Chen, W. (2017). Trends of spray drying: A critical review on drying of fruit and vegetable juices. Trends in Food Science \& Technology, 65(July), 49-67. http://dx.doi.org/10.1016/j.tifs.2017.05.006

Sinela, A., Rawat, N., Mertz, C., Achir, N., Fulcrand, H., \& Dornier, M. (2017). Anthocyanins degradation during storage of Hibiscus sabdariffa extract and evolution of its degradation products. Food Chemistry, 214, 234-241. PMid:27507471. http://dx.doi.org/10.1016/j.foodchem.2016.07.071

Singh, C. S., Paswan, V. K., \& Rai, D. C. (2019). Process optimization of spray dried Jamun (Syzygium cumini L.) pulp powder. Lebensmittel-Wissenschaft + Technologie, 109, 1-6. http://dx.doi.org/10.1016/j.Iwt.2019.04.011

Singh, J. P., Kaur, A., Singh, N., Nim, L., Shevkani, K., Kaur, H., \& Arora, D. S. (2016). In vitro antioxidant and antimicrobial properties of jambolan (Syzygium cumini) fruit polyphenols. Lebensmittel-Wissenschaft + Technologie, 65, 1025-1030. http://dx.doi.org/10.1016/j.Iwt.2015.09.038 
Secagem da polpa de Jambolão (Syzygium cumini) em secador de leito de jorro: efeito da clara de ovo como agente carreador de secagem na qualidade do produto

Soares, A. C., \& Pereira, N. R.

Souza, C. R. F., Donida, M. W., Rocha, S. C. S., \& Oliveira, W. P. (2009). The role of colloidal silicon dioxide in the enhancement of the drying of herbal preparations in suspended state. Chemical Engineering Communications, 196(3), 391-405. http://dx.doi.org/10.1080/00986440802359543

Stevens, L. (1991). Egg white proteins. Comparative Biochemistry and Physiology, 100(1), 1-9. PMid:1756612. http://dx.doi.org/10.1016/0305-0491(91)90076-P

Sturm, K., Koron, D., \& Stampar, F. (2003). The composition of fruit of different strawberry varieties depending on maturity stage. Food Chemistry, 83(3), 417-422. http://dx.doi.org/10.1016/S0308-8146(03)00124-9

Tavares, I. M. C., Lago-Vanzela, E. S., Rebello, L. P. G., Ramos, A. M., Gómez-Alonso, S., García-Romero, E., Da-Silva, R., \& Hermosín-Gutierrez, I. (2016). Comprehensive study of the phenolic composition of the edible parts of jambolan fruit (Syzygium cumini (L.) Skeels). Food Research International, 82(April), 1-13. http://dx.doi.org/10.1016/j.foodres.2016.01.014

Tonon, R. V., Brabet, C., \& Hubinger, M. D. (2009). Influência da temperatura do ar de secagem e da concentração de agente carreador sobre as propriedades físico-químicas do suco de açaí em pó. Food Science and Technology (Campinas), 29(2), 444-450. http://dx.doi.org/10.1590/S0101-20612009000200034

Truong, V., Bhandari, B. R., \& Howes, T. (2005). Optimization of co-current spray drying process of sugar-rich foods. Part I: Moisture and glass transition temperature profile during drying. Journal of Food Engineering, 71(1), 55-65. http://dx.doi.org/10.1016/j.jfoodeng.2004.10.017

Turchiuli, C., Eloualia, Z., El Mansouri, N., \& Dumoulin, E. (2005). Fluidised bed agglomeration: Agglomerates shape and enduse properties. Powder Technology, 157(1), 168-175. http://dx.doi.org/10.1016/j.powtec.2005.05.024

Veigas, J., Narayan, M., Laxman, P., \& Neelwarne, B. (2007). Chemical nature, stability and bioefficacies of anthocyanins from fruit peel of Syzygium cumini Skeels. Food Chemistry, 105(2), 619-627. http://dx.doi.org/10.1016/j.foodchem.2007.04.022

Vizzoto, M., \& Fetter, M. (2012). Jambolão: O poderoso antioxidante. Brasília: Embrapa. Retrieved in 2012, July 5, from https://ainfo.cnptia.embrapa.br/digital/bitstream/CPACT2010/12299/1/jambolao-Marcia.pdf

Weber, F., Boch, K., \& Schieber, A. (2017). Influence of copigmentation on the stability of spray dried anthocyanins from blackberry. Lebensmittel-Wissenschaft + Technologie, 75, 72-77. http://dx.doi.org/10.1016/j.Iwt.2016.08.042

Financiamento: Coordenação de Aperfeiçoamento de Pessoal de Nível Superior (CAPES) (processo n. 001) e Fundação Carlos Chagas Filho de Amparo à Pesquisa do Estado do Rio de Janeiro (FAPERJ) (processo n. E26/202.858/2015). 